\title{
Relationship between larval settlement, alongshore wind stress and surface temperature in a numerical model of the central California coastal circulation
}

\author{
Patrick T. Drake ${ }^{1, *}$, Christopher A. Edwards ${ }^{1}$, Steven G. Morgan ${ }^{2,3}$ \\ ${ }^{1}$ Ocean Sciences Department, University of California Santa Cruz, Santa Cruz, California 95064, USA \\ ${ }^{2}$ Bodega Marine Laboratory, University of California Davis, Bodega Bay, California 94923, USA \\ ${ }^{3}$ Department of Environmental Science and Policy, University of California Davis, Davis, California 95616, USA
}

\begin{abstract}
Variations in larval settlement in coastal upwelling regions such as the California Current System (CCS) have been attributed to variations in physical forcing at various time and space scales, but existing findings are often conflicting and fail to explicitly consider larval transport and swimming behavior. Using virtual larvae in a realistic simulation of the CCS, temporal relationships between wind stress, temperature and nearshore settlement in central California are explored for several vertical swimming behaviors, given a pelagic larval duration (PLD) of 20 to $22 \mathrm{~d}$. A robust negative correlation between upwelling-favorable, PLD-averaged wind stress and settlement was found at timescales of days to years for larvae exposed to the surface boundary layer (SBL), while settlement for larvae that remain below the layer throughout development is increased, and their overall settlement is $\sim 2$ to 20 times higher. A 20 d running mean of the wind stress can account for 52 to $86 \%$ of logit-transformed settlement variance over the $6 \mathrm{yr}$ study period. Wind stress and settlement are coherent at all intra-annual periods greater than the PLD. Monthly climatological cycles of PLD-averaged wind stress and transformed settlement are nearly identical for behaviors exposed to the SBL and constitute $\sim 80 \%$ of the monthly variance. Monthly anomalies of wind stress and settlement are also significantly correlated. Nearshore surface temperature is also well correlated with settlement, but significantly less so than wind stress on both seasonal and intra-seasonal timescales. Other PLDs ranging from 10 to $40 \mathrm{~d}$ displayed similar results. Physical forcing in this model is found to dominate intrinsic eddy variability in driving settlement.
\end{abstract}

KEY WORDS: Wind stress · Upwelling $\cdot$ Larval transport · Dispersal $\cdot$ Recruitment $\cdot$ California Current

\section{INTRODUCTION}

Marine ecologists have often proposed that winddriven currents in coastal upwelling regions strongly affect nearshore larval settlement, thereby influencing the structure and dynamics of intertidal and subtidal communities (Sponaugle et al. 2002, Pineda et al. 2010). Within the California Current System (CCS), nearshore dynamics are dominated by the alongshore wind stress (Checkley \& Barth 2009, García-Reyes \& Largier 2012), which drives cross-shore Ekman transport in the surface boundary layer (SBL)
(Dever et al. 2006). Upwelling-favorable (equatorward) wind stress drives offshore transport in the SBL, which leads to upwelling of cold subsurface water near the coast and onshore or reduced offshore transport at depth. The reverse cross-shore pattern occurs during downwelling-favorable (poleward) wind stress, with onshore transport in the SBL and offshore transport subsurface. If passive larvae remain within the SBL, they should be transported offshore during upwelling and onshore during downwelling by near-surface currents (Roughgarden et al. 1988). Larvae that remain below the SBL should 
experience the reverse pattern. This wind-driven variation in larval supply can potentially affect settlement, recruitment and ultimately community structure and population dynamics, and has strongly influenced the thinking of marine ecologists over the past few decades (Shanks \& Shearman 2009, Pineda et al. 2010).

Within the CCS, observations of larval recruitment have offered substantial evidence for these proposed patterns of wind-related recruitment, though with inconsistent and sometimes conflicting results. Several field studies have found a negative association between upwelling-favorable wind stress (and its associated decrease in nearshore temperature) and recruitment within upwelling seasons (Farrell et al. 1991, Wing et al. 1995, Shkedy \& Roughgarden 1997, Dudas et al. 2009a, Morgan et al. 2009a) and across years (Roughgarden et al. 1988, Connolly \& Roughgarden 1999, Shanks \& Roegner 2007, Iles et al. 2012). Yet one of the most comprehensive studies in the CCS found no significant correlation between monthly anomalous temperature and intertidal recruitment at most sites (Broitman et al. 2008). Upwelling-favorable wind stress has also been associated with increased larval retention and settlement, and this increase has been attributed to direct transport effects owing to pelagic larval behavior (Shanks \& Brink 2005, Dudas et al. 2009a, Morgan et al. 2009b, Shanks \& Shearman 2009, Fisher et al. 2014) and to an indirect influence of upwelling-increased food availability (Laidig et al. 2007, Wilson et al. 2008, Caselle et al. 2010). Recruitment can also appear unrelated to nearshore larval supply due to settling behavior, the patchiness of larval supply, postsettlement predation and other factors (Rilov et al. 2008, Dudas et al. 2009b, Shanks 2009, Pineda et al. 2010), confusing any potential link to wind stress.

Some modeling studies find near-surface larvae are swept offshore during periods of upwellingfavorable wind stress. This transport decreases nearshore retention and settlement during extended upwelling events (Kim \& Barth 2011, Harrison \& Siegel 2014) and over the entire upwelling season (Petersen et al. 2010, Drake et al. 2011). Yet other modeling studies suggest that this effectively 2dimensional description of wind-driven larval transport is too simplistic. Mitarai et al. (2008) find that the intrinsic mesoscale eddy variability in 3-dimensional numerical models can disrupt the above 2-dimensional circulation pattern. Variable mesoscale eddies provide an unpredictable, stochastic forcing on larval export from and delivery to the nearshore region. They significantly alter alongshore connectivity matrices that describe probabilities of larval release and settlement (Siegel et al. 2008). While these studies focused on alongshore variability in connectivity, they highlight how intrinsic variability in ocean circulation can overwhelm local wind stress forcing and significantly alter 2-dimensional expectations.

Motivated by these varied studies both in the observational and modeling literature, we investigate the statistical relationship between alongshore wind stress and larval settlement on various timescales in a coastal upwelling system using a realistic numerical model. As many observational studies have found an association between temperature and settlement, we also examine surface temperature. Wind stress and surface temperature are spatially averaged over a nearshore subdomain, and we use nearshore larval abundance (larval supply) as a proxy for settlement. We focus on central California (Monterey Bay to Cape Mendocino; Fig. 1), which is a zone of persistent spring and summer upwelling-

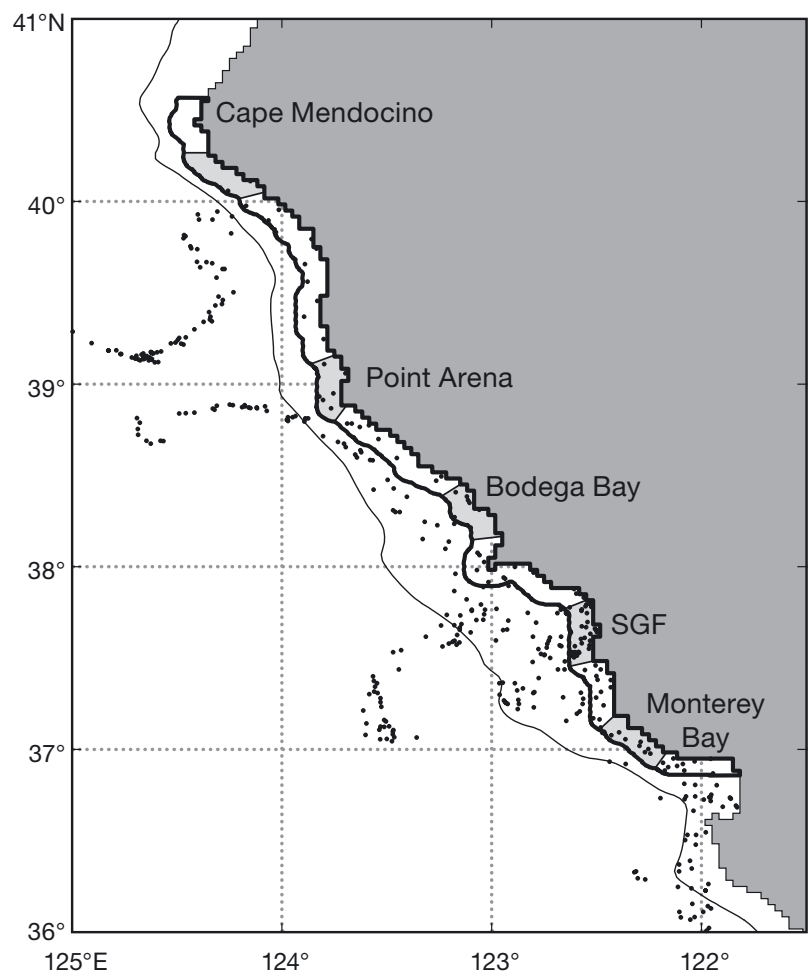

Fig. 1. Central Californian study area, a subdomain of the full model. Heavy line designates the nearshore zone where larvae were released and could settle. Fine line is the $500 \mathrm{~m}$ isobath. Lightly shaded areas within the nearshore zone indicate subregions used in Table 7. Dots indicate locations of 400 DVM (diel vertical migration) larvae released uniformly in the nearshore zone on 2 May 2002, pictured 5 d after release and subsequent entrainment in several filaments. SGF: southern Gulf of the Farallones 
favorable wind stress (García-Reyes \& Largier 2012) and seasonal recruitment of intertidal invertebrates (Broitman et al. 2008). Larvae are released nearshore and near-surface, a scenario potentially appropriate for many intertidal species (Broitman et al. 2008).

Although we exclude several complicating biological factors, such as varying fecundity, settling behaviors, post-settlement mortality, predation, competition, growth and food-availability, we do investigate 4 vertical swimming behaviors to better understand how wind-driven circulation may impact a wide variety of organisms. Specifically, we consider (1) passive larvae (i.e. no behavior); (2) near-surface larvae (i.e. larvae remain mostly within the SBL); (3) deeper larvae (i.e. larvae remain mostly below the SBL); and (4) diel vertical migration (DVM) (i.e. larvae reside below the SBL during the day and in the layer at night). The passive case is a null hypothesis for most coastal invertebrates (Pineda et al. 2007). Drake et al. (2013) found that avoiding the SBL was critical for larvae to settle in substantial numbers during spring in central California. Here we investigate the time dependence of settlement both within seasons and throughout the year for a variety of behaviors.

\section{METHODS}

\section{Regional Ocean Modeling System model}

The implementation of the Regional Ocean Modeling System (ROMS) (Shchepetkin \& McWilliams 2005) and associated offline particle-tracking model used is described and evaluated in Drake et al. (2011, 2013). The model domain covers all of the US portion of the CCS, extending northward from 30 to $48^{\circ} \mathrm{N}$, and westward from 115.5 to $134^{\circ} \mathrm{E}$ (for clarity, only a subdomain directly relevant to central California settlement is shown in Fig. 1). The model uses a $\sim 3.5 \mathrm{~km}$ spatial resolution with 42 vertical levels and was forced at the surface by daily averaged fields from the Coupled Atmospheric Mesoscale Prediction System (COAMPS) (Doyle et al. 2009). It was run for $6 \mathrm{yr}$ from 2001 to 2006, a period of available forcing and existing evaluation with physical observations (Drake et al. 2011, 2013).

Although this model implementation is realistic, riverine influences and tidal motion are not included. Outflow from major estuaries such as San Francisco Bay or smaller rivers during winter months may influence nearshore transport and settlement in their vicinity. Although the $\sim 3.5 \mathrm{~km}$ resolution of this model is relatively high for such a large area domain, transport processes within the most nearshore grid cell are not well represented. It may be that these influences weaken the statistical relationships between wind stress, temperature and settlement explored in this study.

\section{Larval transport}

Approximately 1300 larvae were simultaneously released every other day within a zone extending $10 \mathrm{~km}$ offshore (i.e. the nearshore zone; heavy line in Fig. 1). Larvae were released with roughly equal areal density. As described in Drake et al. (2013), most of the modeled larval transport away from the central California coast during spring was confined to a surface layer $20 \mathrm{~m}$ thick, the nominal SBL. Larvae remaining in this layer (in-SBL case) were given a normal vertical distribution centered about $5 \mathrm{~m}$ depth with a standard deviation (SD) of $2.5 \mathrm{~m}$, ensuring $95 \%$ were confined to a near-surface layer $10 \mathrm{~m}$ thick throughout their pelagic larval duration (PLD). Larvae remaining below the SBL (below-SBL case) were given a similar Gaussian distribution centered at $30 \mathrm{~m}$, a depth predominantly below most of the springtime offshore Ekman transport in the model. Larvae undergoing DVM alternated between these 2 depth distributions every $12 \mathrm{~h}$. Passive larvae were designed to mimic non-swimming, neutrally buoyant larvae that have no control over their depth and move only when advected by the 3-dimensional ocean currents. However, the model does not directly resolve subgrid-scale turbulence, which can mix larvae vertically in the real ocean. To simulate this turbulent mixing, passive larvae were mixed only vertically using a random walk model described in Drake et al. (2013). They were given an initial uniform vertical distribution within a depth range of 0 to $20 \mathrm{~m}$. Passive larvae later ranged over the upper $\sim 100 \mathrm{~m}$ of the water column due to both turbulent mixing and vertical advection. But at any given time, most were in or near the SBL, with $>50 \%$ above $25 \mathrm{~m}$ throughout their PLD.

\section{Settlement}

Larvae settled when occurring within the nearshore zone during their settlement window, which varied with PLD. Larvae that left the nearshore zone could eventually settle if they returned during their settlement window, but most did not return. Settlement was defined as the fraction of larvae released 
that settled, and unless otherwise noted, was referenced to release day. We concentrate on a PLD with a settlement window of 20 to $22 \mathrm{~d}$, but also explore PLDs of 10 to 12,20 to 30 and 40 to $42 \mathrm{~d}$. Our primary PLD of 20 to $22 \mathrm{~d}$ is within the range of many nearshore species, including some of the most abundant species on rocky shores, such as the barnacle Balanus glandula (Roughgarden et al. 1988), Chthamalus spp. barnacles and the mussel Mytilus californianus (Broitman et al. 2008). The choice of a relatively short settlement window ( $3 \mathrm{~d}$ ) reduces uncertainty in the temporal extent of the wind stress experienced by the larvae, allowing for a more direct statistical comparison with settlement.

In spring and summer, there were many instances of little or no settlement for the DVM, in-SBL and passive cases (Fig. 2), resulting in highly positively skewed settlement distributions for these behaviors. Strong upwelling-favorable wind stress during these
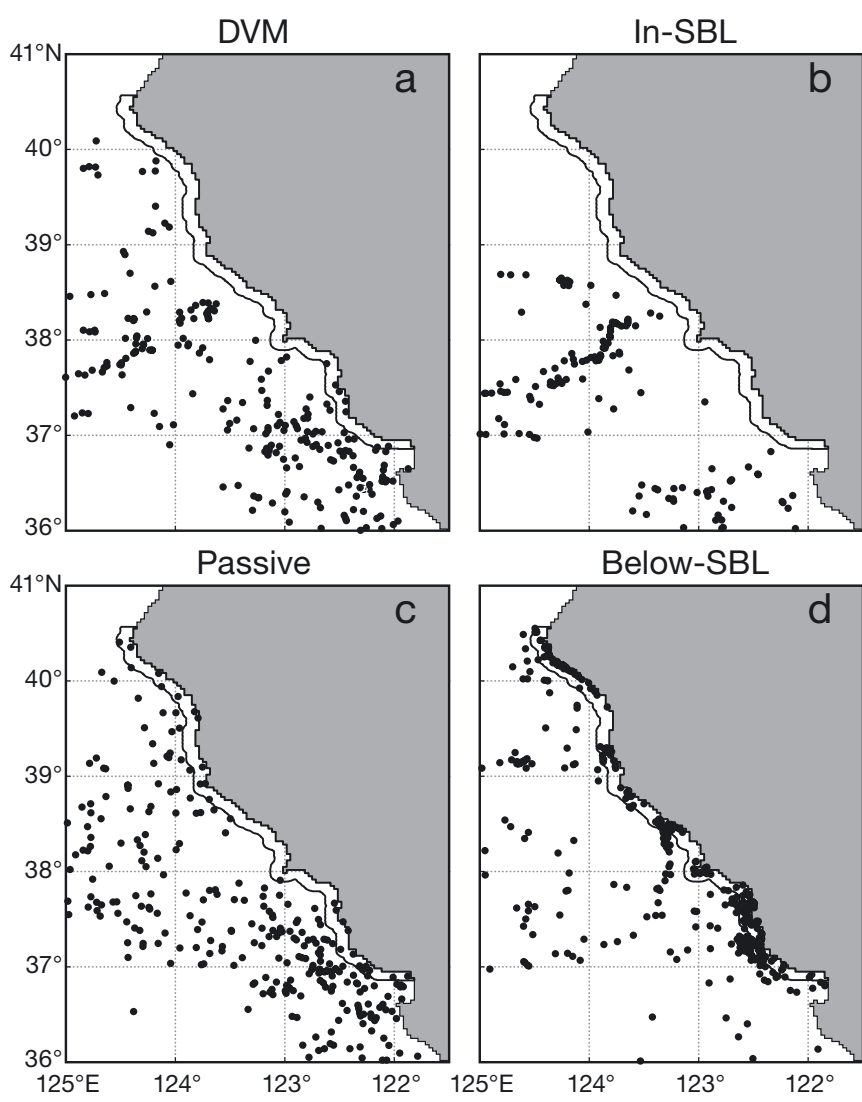

Fig. 2. One example release, showing virtual larvae $20 \mathrm{~d}$ after release, given different vertical swimming behaviors. Four hundred larvae were released uniformly in the nearshore zone (fine line) on 2 May 2002. (a) DVM: larvae performed diel vertical migration; (b) in-SBL: larvae remained in the surface boundary layer; (c) passive: larvae exhibited no behavior; (d) below-SBL: larvae tremained below the surface boundary layer periods often depleted the nearshore of most larvae relatively quickly. If this removal occurred early in the PLD, any further changes in wind stress were acting on few remaining larvae, diminishing the effect of wind stress on settlement and obscuring the connection between the 2 variables. Therefore settlement for all behaviors was logit transformed, where logit $(s)=$ $\log (s /[1-s]), s$ is the fraction settling or (number settling +1$) /($ number released), and at least one larva was always assumed to settle to avoid zeros. This transformation increases the sensitivity of settlement to wind stress at low settlement values, and slightly increases correlation magnitudes between both settlement and wind stress, and settlement and temperature. For all behaviors and PLDs, this transformation also increased the apparent normality of settlement in histograms and quantile function (Q-Q) plots. The logit transform also reduced the Kolmogorov-Smirnov statistic relative to untransformed, square-root-transformed and log-transformed settlement for the primary PLD. When subsampled to account for temporal autocorrelation, a null hypothesis of normality for logit-transformed settlement could not be rejected at the 0.05 significance level using Lilliefors' test (Lilliefors 1967) for all behaviors given the primary PLD. Unless otherwise stated, all settlement statistics refer to logit-transformed values. But an analysis using untransformed values yielded the same overall conclusions as that of the transformed case, specifically that wind stress is a dominant driver of potential settlement and is a better predictor of settlement than surface temperature.

\section{Time series analysis}

Multiple time series of wind stress and surface temperature were calculated to thoroughly analyze their relationships with settlement; these are summarized in Table 1. Both surface temperature and wind stress were averaged over the nearshore zone, and the wind stress projected alongshore $\left(330^{\circ}\right.$, positive poleward). In central California, alongshore winds are spatially coherent over alongshore separation scales of $\sim 500 \mathrm{~km}$ or more (Halliwell \& Allen 1987). Results are not substantially sensitive to the exact choice of alongshore direction or averaging domain. Two day averages were calculated to match the larval release interval and are referred to as $2 \mathrm{~d}$ wind stress and temperature. Settlement and wind stress did not show significant long-term trends, but a linear trend of $0.084^{\circ} \mathrm{C}^{-1}{ }^{-1}$ was removed from the temperature record. 
Table 1. Time series definitions. PLD: pelagic larval duration; SW: settlement window

\begin{tabular}{|c|c|}
\hline Time series name(s) & Description \\
\hline Settlement & $\begin{array}{l}\text { Logit transform of the fraction of larvae released that } \\
\text { settle during their settlement window, referenced to } \\
\text { release day }\end{array}$ \\
\hline Two day wind stress and temperature & $\begin{array}{l}\text { Two day averaged wind stress or temperature, referenced } \\
\text { to the first day in the average }\end{array}$ \\
\hline PLD-averaged wind stress & $\begin{array}{l}\text { Wind stress averaged from larval release to the opening } \\
\text { of the settlement window, referenced to release day }\end{array}$ \\
\hline SW-averaged temperature & $\begin{array}{l}\text { Temperature averaged over the settlement window, } \\
\text { referenced to release day }\end{array}$ \\
\hline Monthly settlement, wind stress and temperature & $\begin{array}{l}\text { Centered, calendar-month average of settlement, PLD- } \\
\text { averaged wind stress or SW-averaged temperature }\end{array}$ \\
\hline Climatological settlement, wind stress and temperature & $\begin{array}{l}\text { Average across years of monthly settlement, wind stress } \\
\text { or temperature }\end{array}$ \\
\hline Monthly anomalous settlement, wind stress and temperature & $\begin{array}{l}\text { Difference between monthly settlement, wind stress or } \\
\text { temperature and its monthly climatology }\end{array}$ \\
\hline Anomalous settlement, wind stress and temperature & $\begin{array}{l}\text { Difference between settlement, PLD-averaged wind } \\
\text { stress or SW-averaged temperature and its linearly } \\
\text { interpolated monthly climatology (bi-daily time series) }\end{array}$ \\
\hline
\end{tabular}

A running average of wind stress was calculated from larval release to the opening of the settlement window for each PLD and referenced to the release day. For the 20 to 22 d PLD, for example, days 0 to 20 from release were averaged and associated with the release date. This bi-daily (every other day) time series is referred to as PLD-averaged wind stress. As will be shown in 'Results: Seasonal patterns and climatological cycles', the PLD-averaged wind stress proves to be an excellent predictor of settlement, better than either the $2 \mathrm{~d}$ average or an average over the settlement window. In contrast, temperature was found generally to be a better predictor of settlement when averaged over the settlement window rather than over the PLD. This improvement was observed for the 10 to 12 and 20 to 22 d PLDs and for all PLDs given the anomalous temperature record (defined below). We therefore concentrate on temperature averaged over the settlement window and referenced to release day, and we refer to this time series as SW-averaged temperature.

Wind stress, temperature and settlement all display predictable, seasonal cycles that can dominate their variances and statistics (Broitman et al. 2008, GarcíaReyes \& Largier 2012). As many studies take place within an individual season, it can be helpful to remove these cycles and isolate shorter-term variability. Here, mean seasonal cycles are represented by monthly climatologies, defined as the average value of a variable within a given calendar month over all 6 yr of the study. This monthly averaging was applied to transformed settlement, PLD-averaged wind stress and SW-averaged temperature, yielding monthly climatologies and monthly anomalies. Bi-daily anomalies were then defined as deviations of transformed settlement, PLD-averaged wind stress and SW-averaged temperature from linearly interpolated monthly climatologies. Thus bi-daily anomalies comprise mainly high-frequency fluctuations that remain when the seasonal cycle is removed.

Correlation coefficients between time series are computed at various lags, providing a measure of overall covariation between 2 signals. To more explicitly examine the relationships between these signals over multiple timescales, it is convenient to analyze them through Fourier decomposition, in which each time series is projected onto a finite sum of sines and cosines having differing frequencies. The power spectrum, or autospectral density function, provides the power (squared amplitude) of a signal in each frequency band, and it can be plotted equivalently as a function of period, as we do here. The coherence function, or simply coherence, is defined as the squared magnitude mean cross-spectral density of 2 time series normalized by the product of the 2 individual mean autospectral density magnitudes (Bendat \& Piersol 2000). The coherence ranges from 0 to 1 and conveys covariation (analogous to the square of the correlation coefficient) as a function of frequency (or period). The coherence can reveal that 2 time series have no covariation at some frequencies 
(coherence near 0), but substantial covariance at other frequencies (coherence near 1). The phase of the cross-spectral density describes the mean temporal offset or lag of the 2 signals at a given frequency, expressed as an angle in radians. The coherence was calculated by subdividing each time series into annual sections (with $50 \%$ overlap), removing a linear trend, multiplying by a Hanning window, calculating spectra with the discrete Fourier transform and finally averaging spectra across sections. Significance levels for the coherence were determined as described in Drake et al. (2005). Effective degrees of freedom for significance levels for correlation coefficients were calculated using the integral timescale of the data. Statistical tests described are considered significant at the $5 \%$ level.
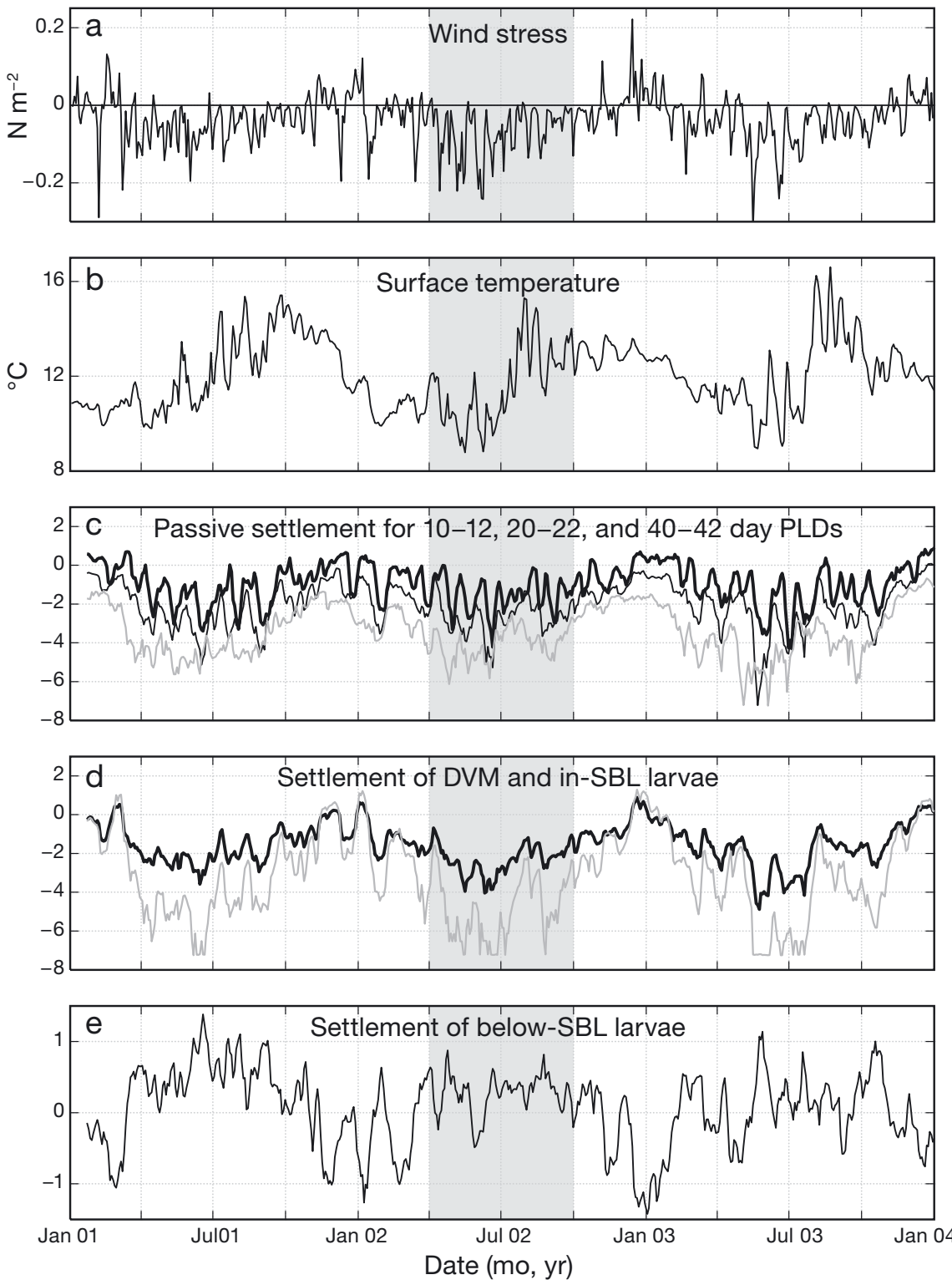

Fig. 3. (a) Two day alongshore wind stress for 3 yr of the 6 yr study, abbreviated for clarity; (b) $2 \mathrm{~d}$ surface temperature; (c) transformed passive settlement, given PLDs of 10-12 d (heavy line), 20-22 d (fine line), and 40-42 d (gray line); (d) transformed settlement of DVM (heavy line) and in-SBL (gray line) behaviors, given a 20-22 d PLD; (e) below-SBL transformed settlement, given a 20-22 d PLD. Shaded areas represent April to September 2002, a selected upwelling season shown in Figs. 4 \& 6, Table 6. DVM: diel vertical migration; PLD: pelagic larval duration; SBL: surface boundary layer

\section{RESULTS}

\section{Seasonal patterns and climatological cycles}

Time series of $2 \mathrm{~d}$ wind stress, $2 \mathrm{~d}$ surface temperature and transformed settlement for all modeled behaviors display clear seasonal patterns (Fig. 3). In spring, the strengthening of the North Pacific high-pressure system produces a cross-shore pressure gradient that drives consistent, equatorward, upwelling-favorable wind stress in central California (GarcíaReyes \& Largier 2012). These upwelling-favorable spring and summer conditions are interrupted occasionally by relaxation events characterized by near-zero wind stress and local peaks in surface temperature. Unlike wind stress, peak seasonal temperatures in the model occur in mid-summer or early fall due to the seasonality of surface heating and the surrounding California Current, consistent with buoy observations (García-Reyes \& Largier 2012). Persistent equatorward springtime wind stress typically leads to reduced temperature and always leads to seasonally reduced settlement for the DVM, passive and in-SBL behaviors. Settlement for these behaviors increases dramatically during fall and winter as the North Pacific highpressure system weakens and shifts southward, wind stress is weakest but most positive, and offshore Ekman transport is minimal. In contrast, settlement for the below-SBL behavior is typically high in spring and summer and lowest in December or January, with less overall variability relative to 

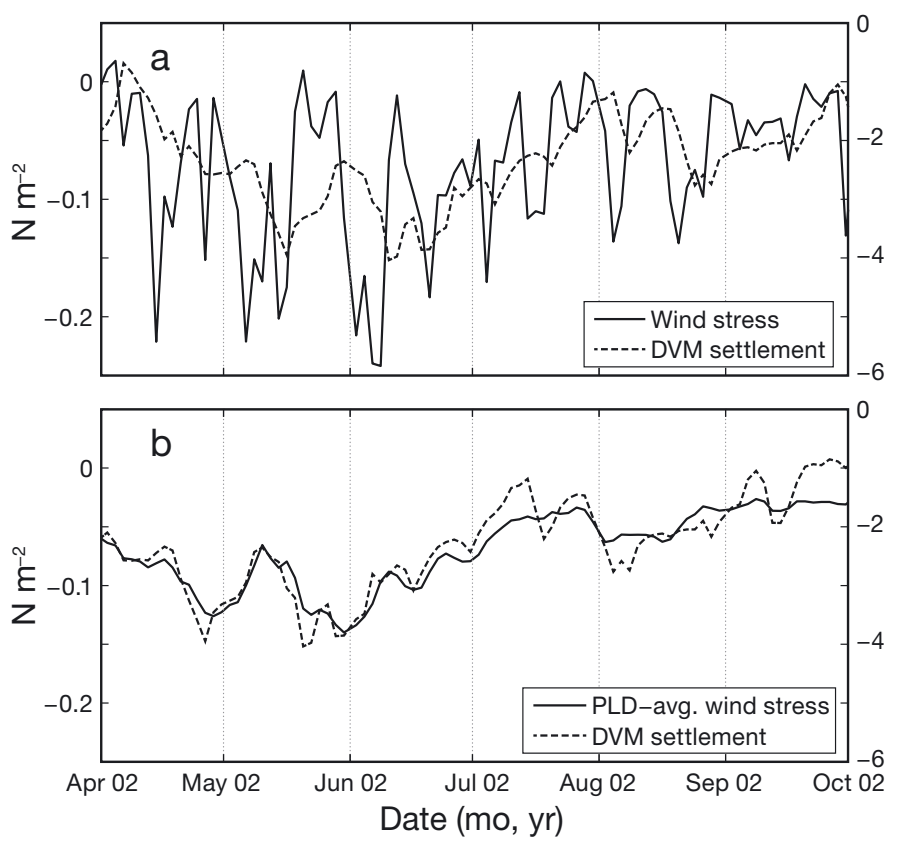

Fig. 4. (a) Two day wind stress and DVM settlement, given a 20-22 d PLD, both referenced to the opening of the settlement window; (b) PLD-averaged wind stress and DVM settlement, both referenced to larval release day. For abbreviations see Fig. 3

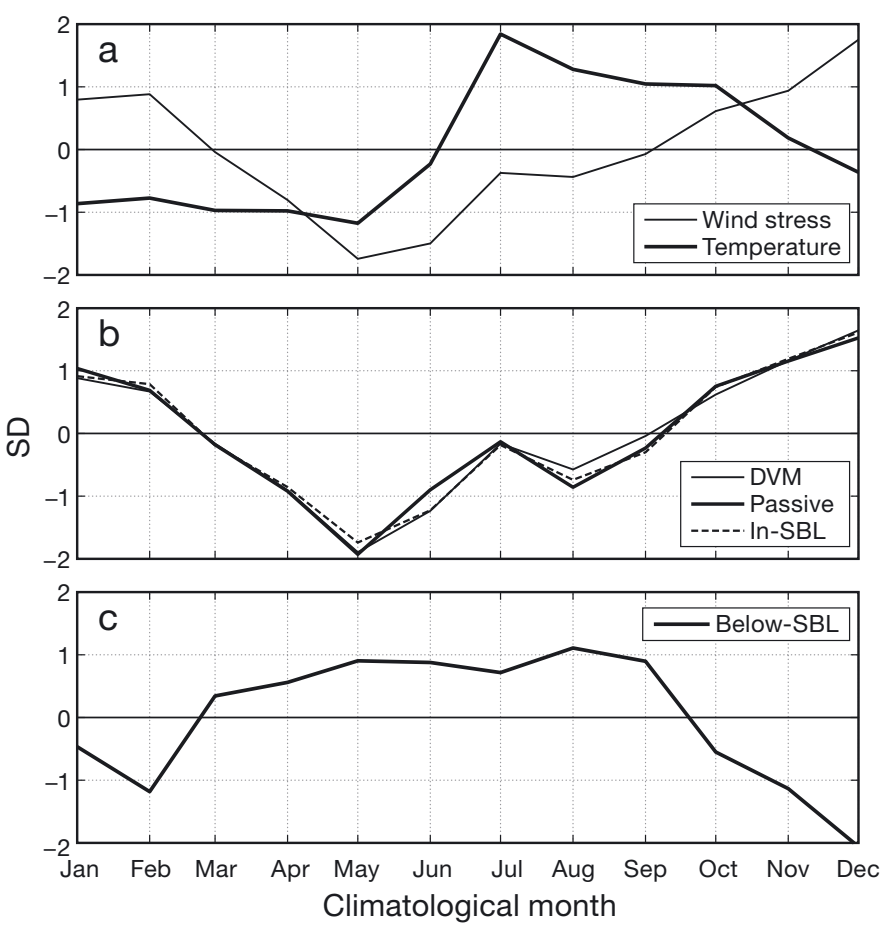

Fig. 5. Monthly climatological cycles, given a 20-22 d PLD, shown in standard deviation (SD) units. (For display only, the mean is removed from each climatology, and the result is then normalized by its sample SD.) (a) PLD-averaged wind stress and SW-averaged surface temperature; (b) DVM, passive and in-SBL settlement; (c) below-SBL settlement. SW:

settlement window; for other abbreviations see Fig. 3 the other behaviors. For passive larvae, increasing PLD duration nearly uniformly lowers settlement strength (Fig. 3c).

The relationship between settlement and wind stress over shorter timescales can be seen more clearly by examining DVM settlement with a 20 to $22 \mathrm{~d}$ PLD $\vec{c}$ for one spring and summer (Fig. 4). Although both time series have the same long-term structure over this particular upwelling season (Fig. 4a), 2 d wind stress displays much more short-term variability than settlement. Here, both wind stress and settlement are referenced to the opening of the settlement window, as typically done in field studies. If the wind stress is PLD-averaged, however, and both time series referenced to release time, they appear highly correlated, with little or no time lag between them (Fig. 4b). Their statistical correlations also increase substantially and significantly. For example, over the entire study, the correlation coefficient of DVM settlement and $2 \mathrm{~d}$ wind stress is $0.54\left(\mathrm{p}<0.001, \mathrm{~N}^{*}=66\right.$, where $\mathrm{p}$ is the likelihood of obtaining the correlation by chance and $\mathrm{N}^{*}$ is the effective degrees of freedom), while the correlation with PLD-averaged wind stress is $0.93\left(\mathrm{p}<0.001, \mathrm{~N}^{*}=65\right)$. This increase in correlation and synchronization of records is the motivation for using the PLD-averaged wind stress and deriving the monthly values, climatology and anomalies from this time series (Table 1).

Fig. 5 presents climatologies of PLD-averaged wind stress, SW-averaged temperature and transformed settlement given a 20 to 22 d PLD. Here, we plot the time series in SD units to allow seasonal patterns to be more directly comparable. Remarkably, the DVM, passive and in-SBL settlement climatologies collapse nearly onto a single curve. All 3 exhibit minima in May and maxima in December, similar to the wind stress climatology. In contrast, the seasonal cycles of SW-averaged temperature and below-SBL settlement deviate substantially from the wind stress and from each other. Their maxima are in summer (July or August), but the temperature minimum occurs in May and the below-SBL settlement minimum is found in December. The seasonal cycle of temperature is much less predictable than that of wind stress or settlement, with the intensity, timing and breadth of peak summer temperatures varying substantially between years (Fig. 3). For the 20 to 22 d PLD, climatological cycles account for 76 and $67 \%$ of PLD-averaged monthly wind stress and SW-averaged temperature variance, respectively. Seasonal settlement is slightly more predictable for most behaviors, with climatology accounting for 80,79 and $78 \%$ of the monthly DVM, passive and in-SBL variance, respec- 
tively. Seasonal below-SBL settlement is the least predictable, with climatology accounting for $51 \%$ of the monthly variance.

\section{Total settlement}

In addition to displaying a unique temporal response, the below-SBL behavior also yields substantially higher untransformed settlement for the entire study period (Table 2). Total settlement is least for the in-SBL case, regardless of PLD. For a fixed settlement window of $3 \mathrm{~d}$, longer PLDs for each behavior lead to decreased settlement. If the width of the settlement window is increased to $11 \mathrm{~d}$ (20 to $30 \mathrm{~d}$ PLD), settlement increases slightly for all behaviors relative to the 20 to $22 \mathrm{~d}$ case, as the larvae have a longer opportunity to settle. However, the increase is relatively small compared to the total settlement because most settlement in our model occurs near the opening of the settlement window, with later days contributing less and less settlement (Table 3). For all PLDs and behaviors, most untransformed settlement occurs on the opening day of the settlement window. These results are consistent with those of Drake et al. (2013), who found the springtime nearshore retention of larvae in central California could be well modeled statistically as a maximum at release and subsequent exponential decay with time. If mean untransformed settlement is determined from upwelling seasons only (April to September), the value for the below-

Table 2. Total untransformed settlement (fraction of all larvae released that eventually settle). DVM: diel vertical migration; PLD: pelagic larval duration; SBL: surface boundary layer

\begin{tabular}{|lcccc|}
\hline \multirow{2}{*}{ Behavior } & \multicolumn{4}{c|}{ PLD (d) } \\
\cline { 2 - 5 } & $10-12$ & $20-22$ & $20-30$ & $40-42$ \\
\hline Below-SBL & 0.67 & 0.52 & 0.57 & 0.34 \\
DVM & 0.41 & 0.22 & 0.25 & 0.086 \\
Passive & 0.31 & 0.16 & 0.20 & 0.060 \\
In-SBL & 0.27 & 0.14 & 0.16 & 0.056 \\
\hline
\end{tabular}

Table 3. Fraction of untransformed settlement occurring at the beginning of the settlement window given a 20 to $30 \mathrm{~d}$ PLD. For abbreviations see Table 2

\begin{tabular}{|lcc|}
\hline Behavior & Settling day 20 & Settling days 20-22 \\
\hline Below-SBL & 0.84 & 0.90 \\
DVM & 0.74 & 0.85 \\
In-SBL & 0.74 & 0.84 \\
Passive & 0.65 & 0.79 \\
\hline
\end{tabular}

SBL behavior is little changed, but the others decrease substantially for the primary PLD of 20 to $22 \mathrm{~d}$. Upwelling season mean values of untransformed settlement are $0.57,0.12,0.077$ and 0.029 for the belowSBL, DVM, passive and in-SBL cases, respectively, and can be compared with the overall settlement of the 20 to $22 \mathrm{~d}$ PLD in Table 2.

\section{Correlations between settlement and wind stress}

Transformed settlement for all behaviors and PLDs is well correlated with PLD-averaged wind stress (Table 4, top half), consistent with idealized modeling results from surface floats (Harrison \& Siegel 2014). There is little difference in correlation between PLDs. For all PLDs, the zero-lag correlation coefficients for the DVM, passive and in-SBL behaviors are positive with similar magnitudes; the belowSBL value is negative and somewhat weaker. Surprisingly, nearly identical values are obtained for both DVM and in-SBL, despite the fact that the DVM behavior combines in-SBL and below-SBL depth distributions. We now concentrate on the primary PLD of 20 to $22 \mathrm{~d}$. The difference in correlation between below-SBL and the remaining behaviors is significant, but the difference between the passive and DVM cases is not. Using a linear statistical model, PLD-averaged wind stress can account for 52 to $86 \%$ of the bi-daily transformed settlement variance over the entire 6 yr study period, depending on behavior.

Table 4. (a) Correlations of settlement with PLD-averaged wind stress; (b) correlations of anomalous settlement with anomalous wind stress. $\mathrm{N}^{*}$ : effective degrees of freedom accounting for autocorrelation. All correlation coefficients are statistically significant $(p<0.001)$. For abbreviations see Table 2

\begin{tabular}{|lrccc|}
\hline \multirow{2}{*}{ Behavior } & \multicolumn{5}{c}{ PLD (d) } \\
\cline { 2 - 5 } & $10-12$ & $20-22$ & $20-30$ & $40-42$ \\
\hline (a) & & & & \\
DVM & 0.92 & 0.93 & 0.91 & 0.91 \\
In-SBL & 0.94 & 0.93 & 0.91 & 0.86 \\
Passive & 0.88 & 0.87 & 0.84 & 0.83 \\
Below-SBL & -0.70 & -0.72 & -0.71 & -0.73 \\
N* range & $79-92$ & 65 & 65 & 49 \\
(all behaviors) & & & & \\
(b) & & & & \\
DVM & 0.86 & 0.83 & 0.79 & 0.72 \\
In-SBL & 0.90 & 0.83 & 0.79 & 0.69 \\
Passive & 0.80 & 0.73 & 0.69 & 0.56 \\
Below-SBL & -0.70 & -0.66 & -0.63 & -0.52 \\
N* range & $403-409$ & 255 & 255 & 115 \\
(all behaviors) & & & & \\
\hline
\end{tabular}


To test if these high correlations result largely from the annual cycle, we consider anomalous fields in which the climatological cycle has been removed. Fig. 6 presents anomalous wind stress, temperature and settlement for the primary PLD over 1 representative spring and summer in SD units. For some behaviors, bi-daily anomalous settlement and wind stress display similar fluctuations. The visual pattern that is apparent between anomalous wind stress and settlement is supported by statistical correlations that are similar to but smaller than those of the full time series for all behaviors and PLDs (Table 4b, compare with Table $4 \mathrm{a}$ ). For the 20 to $22 \mathrm{~d}$ PLD, the reduction is statistically significant for all behaviors except below-SBL. The reduction results from the extremely

\section{Anomalous wind stress and temperature}

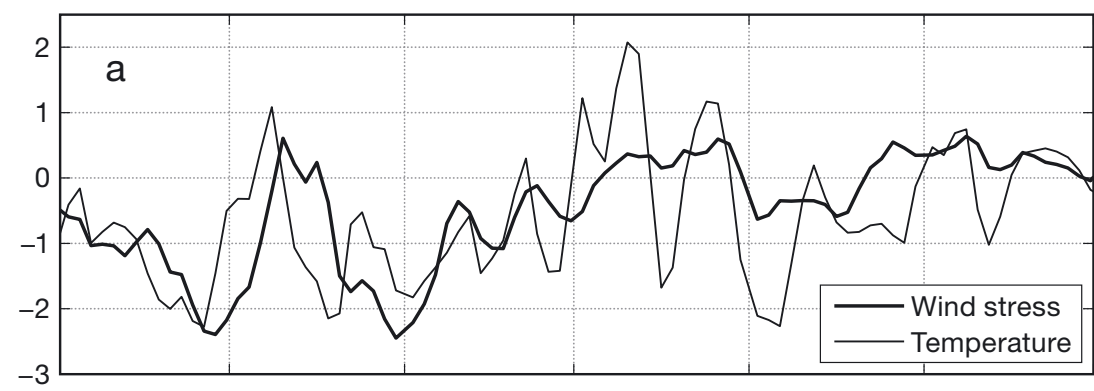

Anomalous wind stress and DVM and in-SBL settlement

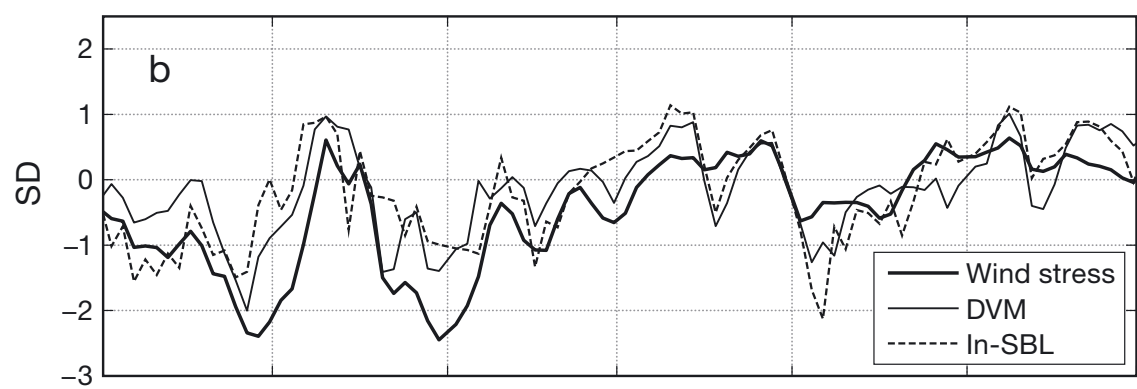

Anomalous wind stress and passive and below-SBL settlement

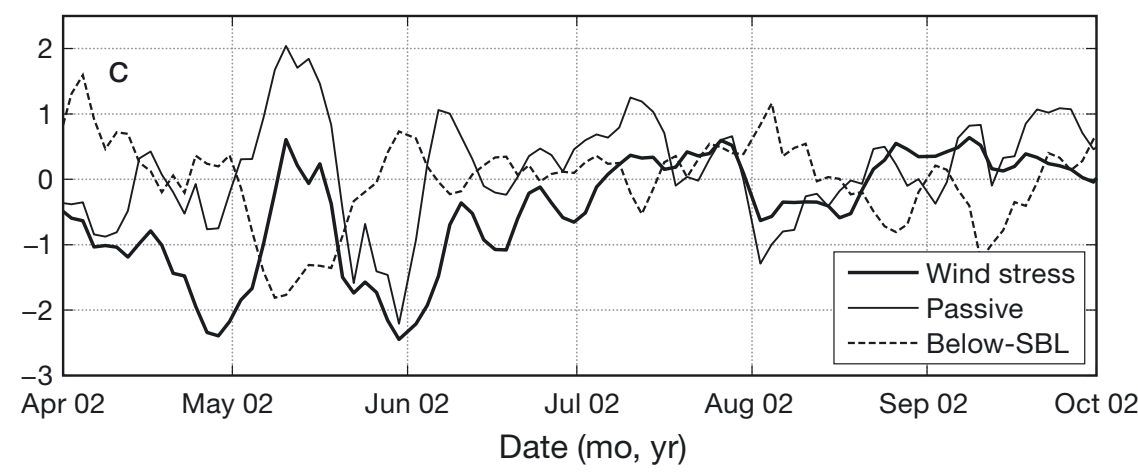

Fig. 6. Anomalous settlement, wind stress and temperature, given a 20-22 d PLD, shown in standard deviation (SD) units. (For display only, each time series is normalized by its sample SD.) For abbreviations see Fig. 3 high correlation of climatological settlement and wind stress $\left(r=0.99, p<0.001, N^{*}=10\right.$, where $r$ is the correlation coefficient), which has been removed. Increasing the PLD decreases the magnitude of the anomalous correlation for all behaviors (Table $4 \mathrm{~b}$ ). This decrease likely results from the intrinsic eddy variability in the model, which disperses the larvae and whose cumulative effects steadily degrade the importance of the wind stress.

The maximum correlation between settlement and PLD-averaged wind stress occurs at the same lag, regardless of whether the climatological cycle is removed (for the primary PLD). For example, if PLDaveraged wind stress is referenced to the center of the PLD and settlement is referenced to the opening of the settlement window (i.e. if they are not deliberately synchronized for analysis), settlement is most correlated with PLD-averaged wind stress when it lags wind stress by 8 to $10 \mathrm{~d}$ for all behaviors (Fig. 7). This lag at half the PLD suggests that the wind stress applied while the larvae are in the water column is most relevant for settlement, as intuitively expected. Anomalous settlement and wind stress display a slightly reduced maximum correlation at the same lag, again for all behaviors (Fig. 7). If all time series are referenced to release time, the lag at maximum correlation becomes 0 to $2 \mathrm{~d}$, confirming the utility of this referencing for nominally synchronizing time series. These results show settlement and PLD-averaged wind stress co-vary at the same lag both on seasonal and intra-seasonal timescales.

\section{Correlations between settlement and temperature}

Settlement displayed a mixed response to temperature. Transformed settlement is not well correlated with SW-averaged temperature (Table 5a). Zero-lag correlation coefficients of settlement with SW-averaged temperature are relatively weak, although significant for all behaviors except below-SBL. In all cases, temperature correlations are less than 


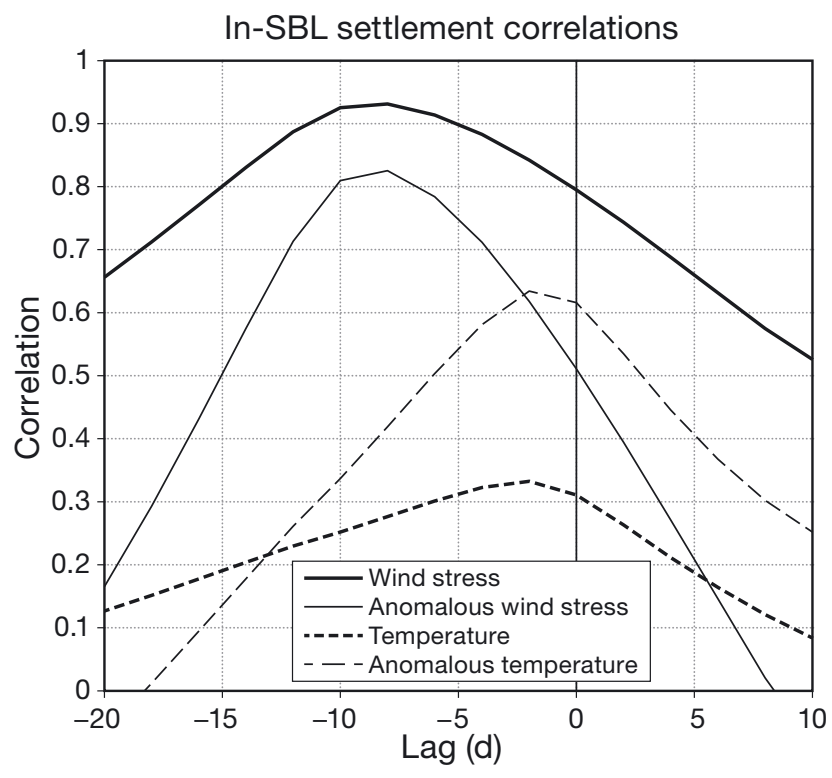

Fig. 7. Correlations of in-SBL settlement versus wind stress or temperature as a function of lag, given a 20-22 d PLD. Zero lag represents the opening of the settlement window. Peak correlations at negative lags indicate wind stress or temperature lead settlement. Wind stress is PLD-averaged in both wind stress comparisons (solid lines). Temperature is SWaveraged in both temperature comparisons (dashed lines). Anomalous wind stress and temperature are paired with anomalous settlement. In this figure, time references differ from those described in Table 1. Settlement and temperature are referenced to the opening of the settlement window (SW), and wind stress is referenced to the center of the PLD. For abbreviations see Fig. 3

Table 5. (a) Correlations of settlement with SW (settlement window)-averaged temperature; (b) correlations of anomalous settlement with anomalous temperature. $\mathrm{N}^{*}$ : effective degrees of freedom accounting for autocorrelation) Bold: statistically significant correlations (in (a) p $<0.05$; in (b) p < 0.001). ${ }^{*} \mathrm{p}<0.05$. For abbreviations see Table 2

\begin{tabular}{|lcccc|}
\hline \multirow{2}{*}{ Behavior } & \multicolumn{5}{c}{ PLD (d) } \\
\cline { 2 - 5 } & $10-12$ & $20-22$ & $20-30$ & $40-42$ \\
\hline (a) & & & & \\
DVM & $\mathbf{0 . 3 4}$ & $\mathbf{0 . 3 3}$ & $\mathbf{0 . 2 7}$ & 0.24 \\
In-SBL & $\mathbf{0 . 3 7}$ & $\mathbf{0 . 3 1}$ & 0.23 & 0.059 \\
Passive & $\mathbf{0 . 3 2}$ & $\mathbf{0 . 2 9}$ & 0.20 & 0.17 \\
Below-SBL & -0.12 & -0.078 & -0.0034 & 0.072 \\
N $^{*}$ range & 70 & $67-72$ & 64 & $55-70$ \\
(all behaviors) & & & & \\
& & & & \\
(b) & & & & \\
DVM & $\mathbf{0 . 5 7}$ & $\mathbf{0 . 6 0}$ & $\mathbf{0 . 5 5}$ & $\mathbf{0 . 6 0}$ \\
In-SBL & $\mathbf{0 . 6 2}$ & $\mathbf{0 . 6 2}$ & $\mathbf{0 . 5 8}$ & $\mathbf{0 . 4 7}$ \\
Passive & $\mathbf{0 . 5 6}$ & $\mathbf{0 . 5 2}$ & $\mathbf{0 . 4 1}$ & $\mathbf{0 . 3 9}$ \\
Below-SBL & $\mathbf{- 0 . 3 1}$ & $\mathbf{- 0 . 2 8}$ & -0.17 & $-0.21^{*}$ \\
N* range & 133 & 134 & 102 & 138 \\
(all behaviors) & & & & \\
\hline
\end{tabular}

the corresponding wind stress values (compare top Tables 5a \& 4a), and significantly so for the primary PLD. However, anomalous settlement and temperature are substantially more correlated at zero-lag than are the full time series (Table 5b, compare with Table 5a). Given the 20 to $22 \mathrm{~d}$ PLD, the increases are significant for all behaviors except below-SBL. Despite the robust correlation of anomalous settlement and temperature, anomalous temperature correlations are always lower than the corresponding wind stress values (compare Tables 5b and $4 \mathrm{~b}$ ). The differences are significant for the primary PLD.

Removing the climatologies of settlement and temperature increases the correlation magnitudes because their seasonal cycles are relatively poorly correlated at zero lag. For example, given the DVM behavior and primary PLD, the zero-lag correlation of climatological settlement and temperature is low and not significant $\left(\mathrm{r}=0.11, \mathrm{p}=0.80, \mathrm{~N}^{*}=10\right)$. The corresponding wind stress value noted earlier is highly significant $(\mathrm{r}=0.99)$. This difference likely results at least in part from the offset between peak seasonal temperature and peak wind stress: temperature is warmest in July due to summertime heating, and wind stress is most northward in December when settlement is also greatest for most behaviors (Fig. 5).

Bi-daily anomalous settlement and temperature are best correlated when settlement lags temperature by 2 d given the primary PLD, regardless of behavior (Fig. 7). The $2 \mathrm{~d}$ lag likely reflects the influence of the PLD-averaged wind stress on both temperature and settlement, rather than a direct link between the latter 2 time series. Anomalous SW-averaged temperature and anomalous PLD-averaged wind stress are best correlated when temperature lags wind stress by $6 \mathrm{~d}\left(\mathrm{r}=0.61, \mathrm{p}<0.001, \mathrm{~N}^{*}=130\right)$. The combination of these 2 lags (between wind stress and temperature, and between temperature and settlement) yields the $8 \mathrm{~d}$ lag observed between wind stress and settlement noted in the previous subsection.

It is common in field studies to restrict analysis to individual upwelling seasons (Farrell et al. 1991, Wing et al. 1995, Shkedy \& Roughgarden 1997, Dudas et al. 2009a, Iles et al. 2012). If we consider only the period from April to September, anomalous wind stress at zero lag is almost always a better predictor of anomalous settlement than is anomalous temperature for the primary PLD. The only exception is the in-SBL behavior during the 2002 upwelling season, when anomalous temperature was a better predictor (Table 6), but the difference from the wind stress correlation was not significant. 
Table 6. Correlations of anomalous settlement with anomalous wind stress or temperature during the 2002 upwelling season (April to September). r: zero-lag correlation coefficient; p: probability of obtaining a value as large as $r$ by chance; $N^{*}$ : effective degrees of freedom accounting for autocorrelation. For other abbreviations see Table 2

\begin{tabular}{|lccccccc|}
\hline \multirow{2}{*}{ Behavior } & \multicolumn{4}{c}{ Anomalous wind stress } & \multicolumn{4}{c|}{ Anomalous temperature } \\
& $\mathrm{r}$ & $\mathrm{p}$ & $\mathrm{N}$ & $\mathrm{N}$ & $\mathrm{p}$ & $\mathrm{N}^{*}$ \\
\hline DVM & 0.75 & $<0.001$ & 35 & 0.63 & $<0.001$ & 47 \\
In-SBL & 0.56 & $<0.001$ & 30 & 0.65 & $<0.001$ & 30 \\
Passive & 0.65 & $<0.001$ & 35 & 0.44 & 0.0047 & 40 \\
Below-SBL & -0.30 & 0.13 & 28 & -0.059 & 0.77 & 28 \\
\hline
\end{tabular}

\section{Variation across subregions}

Analysis of settlement in smaller subregions of the nearshore zone (lightly shaded areas in Fig. 1), yields generally similar results to the regional averages. In this subregional analysis, releases span the entire nearshore zone, wind stress is averaged over this area and settlement is quantified for each subregion. The analysis is restricted to the 20 to $22 \mathrm{~d}$ PLD. The correlation of subregional settlement with PLDaveraged wind stress is always weaker than when considering settlement over the nearshore zone as a whole (Table 7a, compare with Table 4a). But correlation magnitudes remain relatively high, except for the below-SBL case and in the Monterey Bay subregion for the DVM and passive behaviors. If wind stress is averaged only over individual subregions, correlations with settlement decrease slightly (not shown), except for 2 instances of the below-SBL behavior.

In contrast to wind stress, subregional settlement is generally better correlated with temperature when temperature is averaged over individual subregions, rather than the entire nearshore. Settlement in the southern Gulf of the Farallones was an exception. For this reason we present correlations of subregional settlement with subregional SWaveraged temperature (Table $7 \mathrm{~b}$ ). The subregional correlations are generally greater than the regional values for the northern subregions of Cape Mendocino, Point Arena and Bedega Bay (compare Table $7 \mathrm{~b}$ with Table 5a), but may be less for the southern subregions of southern Gulf of the Farallones and Monterey Bay. The below-SBL behavior was an exception to this pattern.

\section{Spectra and coherence}

Time dependence at various frequencies is now investigated using $2 \mathrm{~d}$ wind stress, $2 \mathrm{~d}$ temperature and transformed settlement. Only the primary PLD is considered for simplicity of description. These time series generally display little long-term variability. Interannual trends are nonexistent or small, and the variance at subannual frequencies is almost negligible. We find that less than $2 \%$ of total variance for $2 \mathrm{~d}$ wind stress, less than $10 \%$ for $2 \mathrm{~d}$ temperature and less than $5 \%$ of total settlement variance for all behaviors occurs at subannual frequencies (not shown). Most subannual variance occurs near the annual frequency with periods between 1 and $1.5 \mathrm{yr}$.

Fig. 8a,b presents variance-preserving spectral density functions (or spectra) for annual or higher frequencies, expressed in terms of period for convenience. Variance-preserving spectra have the advantage that the fractional variance contributed by a frequency band is equal to the fractional area under the curve within the band. Thus relative power within ranges of frequencies is more easily comparable. Substantial differences in spectra from the differ-

Table 7. (a) Subregional correlations of settlement with PLD-averaged wind stress given a 20-22 d PLD; (b) subregional correlations of settlement with SW (settlememt window)-averaged temperature given a 20-22 d PLD. Settlement is considered for subregions (lightly shaded areas in Fig. 1), with releases extending throughout the central California nearshore zone (heavy line in Fig. 1); wind stress (a) is averaged over this larger area, and temperature (b) is averaged over individual subregions. $\mathrm{N}^{*}$ (effective degrees of freedom accounting for autocorrelation): (a) 65, and (b) 64 to 96 depending on behavior and subregion. Bold: statistically significant correlations $(p<0.05)$. SGF: southern Gulf of the Farallones. For other abbreviations see Table 2

\begin{tabular}{|c|c|c|c|c|c|}
\hline \multirow[t]{2}{*}{ Behavior } & \multicolumn{5}{|c|}{ Subregion- } \\
\hline & $\begin{array}{c}\text { Cape } \\
\text { Mendocino }\end{array}$ & $\begin{array}{l}\text { Arena } \\
\text { Point }\end{array}$ & $\begin{array}{l}\text { Bodega } \\
\text { Bay }\end{array}$ & SGF & $\begin{array}{c}\text { Monterey } \\
\text { Bay }\end{array}$ \\
\hline \multicolumn{6}{|l|}{ (a) } \\
\hline DVM & 0.78 & 0.83 & 0.82 & 0.73 & 0.34 \\
\hline In-SBL & 0.79 & 0.82 & 0.79 & 0.84 & 0.71 \\
\hline Passive & 0.72 & 0.77 & 0.78 & 0.73 & 0.40 \\
\hline Below-SBL & -0.035 & -0.22 & -0.30 & -0.50 & -0.33 \\
\hline \multicolumn{6}{|l|}{ (b) } \\
\hline DVM & 0.42 & 0.40 & 0.55 & 0.014 & -0.067 \\
\hline In-SBL & 0.35 & 0.31 & 0.35 & -0.035 & 0.15 \\
\hline Passive & 0.32 & 0.36 & 0.46 & 0.089 & -0.034 \\
\hline Below-SBL & 0.044 & -0.073 & -0.32 & 0.083 & -0.43 \\
\hline
\end{tabular}



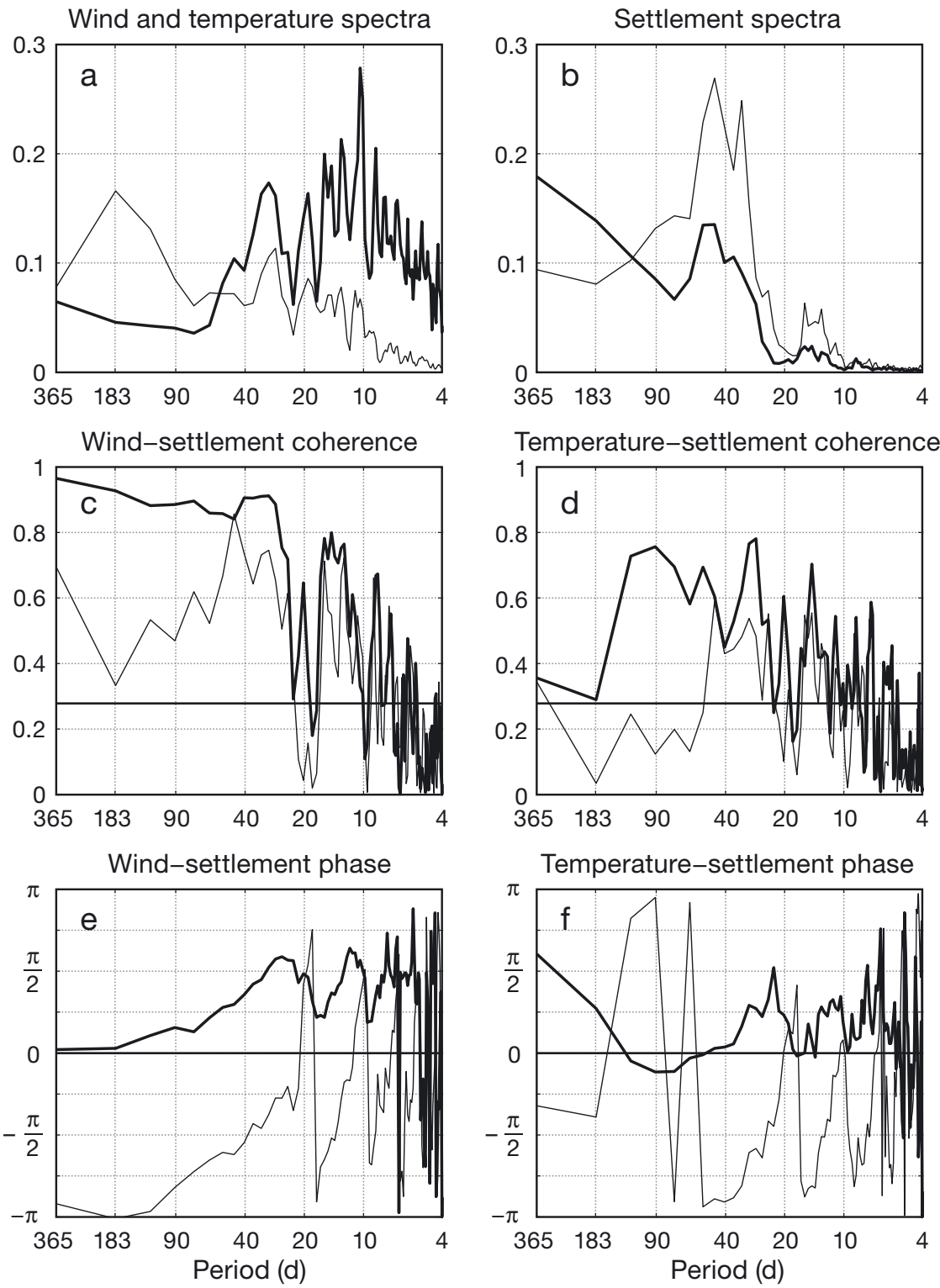

Temperature-settlement coherence

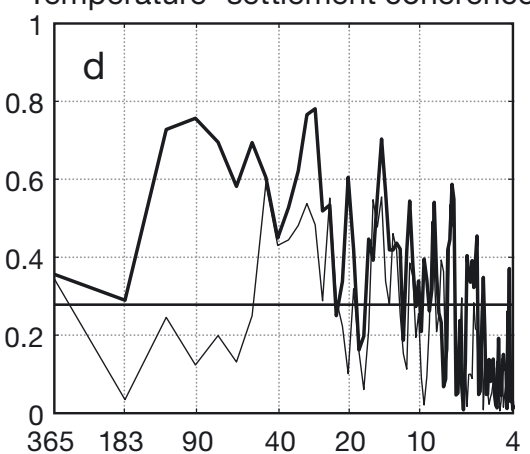

Temperature-settlement phase

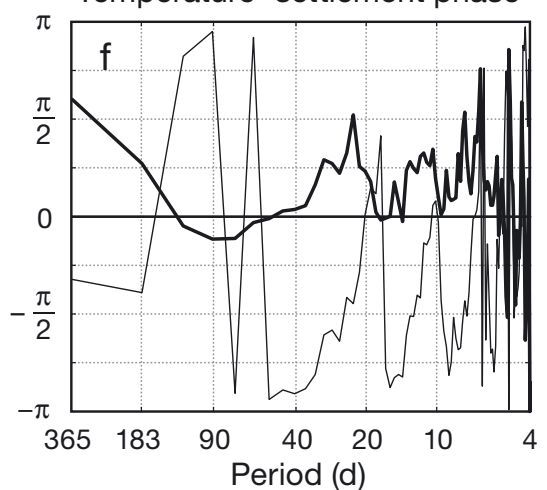

Fig. 8. Variance-preserving spectra, coherence and phase of $2 \mathrm{~d}$ wind stress $2 \mathrm{~d}$ surface temperature and transformed settlement, given a 20-22 d PLD. (a) Wind stress (heavy line) and surface temperature (fine line) spectra in normalized units. (b) DVM (heavy line) and below-SBL (fine line) transformed settlement spectra in normalized units. (c) Coherence of wind stress with DVM (heavy line) and below-SBL (fine line) settlement. (d) Coherence of temperature with DVM (heavy line) and below-SBL (fine line) settlement. Horizontal solid lines in (c) and (d) represent the value at which the coherence differs from zero at the 0.05 significance level. (e) Phase angle in radians between wind stress and DVM (heavy line) and below-SBL (fine line) settlement. (f) Phase angle between temperature and DVM (heavy line) and below-SBL (fine line) settlement. For abbreviations see Fig. 3

ent time series are evident in Fig. 8a,b. The wind spectrum reveals considerable energy at short periods of 4 to $60 \mathrm{~d}$, with relatively less energy at seasonal timescales. In contrast, temperature fluctuations are smallest for periods less than $10 \mathrm{~d}$, and largest at the semi-annual period. Spectra for DVM, passive and in-SBL behaviors are similar, and we show only the DVM case for brevity. There is relatively little variance in settlement at periods shorter than the PLD $(20 \mathrm{~d})$, with generally increased settlement variance at low frequencies. DVM settlement shows a clear increase in energy between about 30 and $60 \mathrm{~d}$. The below-SBL spectrum is similar to the DVM case, but with a larger and broader 30 to $60 \mathrm{~d}$ peak, and less energy at semi-annual and annual timescales.

The coherence function quantifies covariation between signals at each frequency and is presented in Fig. 8c,d. DVM settlement is highly coherent with $2 \mathrm{~d}$ wind stress at periods longer than $25 \mathrm{~d}$ (Fig. 8c). Thus fluctuations in alongshore wind stress are coherent with settlement at those periods where settlement variance is most substantial. Although one can not attribute causation from coherence plots, the very high value for the coherence $(>0.8)$ in combination with an understanding of how wind stress drives ocean currents suggests that wind stress is the dominant factor driving DVM settlement at these low frequencies. Coherence was slightly less for the in-SBL and passive cases (not shown). Finally, the coherence between below-SBL settlement and wind stress is still high and significant, but considerably lower than the DVM case, especially at the semi-annual frequency.

At each frequency, fluctuations between time-varying signals can be coherent but with a quantifiable phase offset that corresponds to a time lag between sinusoidal peaks. This phase offset is itself a function of frequency. In Fig. 8e, the phase angles between DVM settlement and wind stress, and between below-SBL settlement and wind stress are shown. For periods greater than $22 \mathrm{~d}$, the phase angle increases with decreasing period, and this structure suggests a fixed time lag between these variables. For example, at a period of $30 \mathrm{~d}$, the DVM 
behavior shows a phase angle to the wind stress of approximately $\pi / 2$ radians, or a quarter period, representing a $\sim 8 \mathrm{~d}$ lag between 2 sine waves at this frequency. At a period of $60 \mathrm{~d}$, the phase is $\sim \pi / 4$, or oneeighth of a period, but the corresponding lag is unchanged, $\sim 8 \mathrm{~d}$. $\theta=2 \pi(\tau f)$, where $\theta$ is the measured phase, $\tau$ is the assumed constant lag and $f$ is the frequency, yields a best-fit lag of 8 to $10 \mathrm{~d}$, with settlement lagging wind stress. (In this spectral analysis, all time series were referenced to the opening of the settlement window.) This constant lag near the midpoint of the PLD is consistent with settlement being most related to a running mean of the wind stress over the full PLD, which would produce such a lag regardless of frequency.

To investigate how settlement depends on wind stress during the PLD, we consider the following linear model. Let $s(t)=A_{0} W(t-0)+A_{2} W(t-2)+$ $A_{4} W(t-4)+\ldots A_{20} W(t-20)$, where $s$ is the settlement, $w$ is the $2 \mathrm{~d}$ wind stress, $t$ is time and $A$ is the weight of the wind stress at day $t-0, t-2$, etc. Weights chosen to best fit the settlement in a least squares sense are non-zero for the full PLD and increase approximately linearly throughout its duration, with winds late in the PLD having a greater quantitative impact on settlement than early PLD winds. However, this variation in weights is not significant, indicating again that the PLD-averaged wind stress may be the best predictor of settlement. Kim \& Barth (2011) found the cumulative nearshore abundance of both competent and pre-competent larvae released daily off the coast of Oregon was best predicted by a 6 to $8 \mathrm{~d}$ running mean of the wind stress. Our results for this 20 to 22 d PLD suggest that wind stress from release to competency contributes to settlement, consistent with recent idealized modeling experiments (Harrison \& Siegel 2014).

Two day temperature and DVM settlement are also coherent over a broad range of periods from 25 to 120 d (Fig. 8d). Relative to wind stress coherence, they display a reduced amplitude overall and a marked absence of coherence at annual and semiannual frequencies. This lack of coherence is likely a reflection of the inconsistent breadth and timing of the summertime temperature maximum relative to the comparatively predictable spring and summer wind stress minimum. For below-SBL settlement, the coherence with temperature is also smaller than the corresponding coherence with wind stress; it is not significant for most periods greater than $50 \mathrm{~d}$ (Fig. 8d).

\section{Monthly anomalies}

The results show that alongshore wind stress, temperature and settlement are coherent over seasonal timescales, indicating that upwelling seasons with more pronounced equatorward wind stress are associated with decreased settlement. Although these statistics based on bi-daily time series are helpful, some field studies in the CCS employ monthly or annual sampling to investigate seasonal and interannual connections between oceanographic conditions and recruitment. For example, Broitman et al. (2008) found that monthly surface temperature and barnacle recruitment were well correlated along the US west coast, but monthly anomalies less so. Caselle et al. (2010) found a positive association between interannual rockfish recruitment and Bakun upwelling index, and Laidig et al. (2007) found a negative association between interannual rockfish recruitment and temperature. In both cases, the associations were possibly due to increased food availability during springs with strong upwelling conditions. To allow for a more direct comparison with these existing studies, we now explore monthly statistics for the primary PLD. We do not address interannual variability due to the short ( 6 yr) duration of the study.

With the climatological cycles removed, monthly anomalous settlement and wind stress remain well correlated (Table 8). Correlations varied with behavior, but are significant in all cases. Correlations are positive for the DVM, in-SBL and passive behaviors and negative for the below-SBL case, consistent with the bi-daily wind stress results (Table 4). The in-SBL behavior displayed the largest anomalous monthly correlation magnitude with relatively little scatter, while the below-SBL case revealed the most scatter (Fig. 9a,b). Settlement is also significantly correlated with monthly anomalous temperature for all behav-

Table 8. Correlations of monthly anomalous settlement, wind stress and temperature given a 20 to $22 \mathrm{~d}$ PLD. $\mathrm{N}^{*}=70$ in all cases. $r$ : zero-lag correlation coefficient; p: probability of obtaining a value as large as $r$ by chance; $N^{*}$ : effective degrees of freedom accounting for autocorrelation. For other abbreviations see Table 2

\begin{tabular}{|lrrrr|}
\hline Behavior & \multicolumn{3}{c}{$\begin{array}{c}\text { Monthly anomalous } \\
\text { wind stress }\end{array}$} & \multicolumn{2}{c|}{$\begin{array}{c}\text { Monthly anomalous } \\
\end{array}$} & $\mathrm{r}$ & $\mathrm{p}$ & $\mathrm{r}$ & $\mathrm{p}$ \\
\hline DVM & 0.82 & $<0.001$ & 0.67 & $<0.001$ \\
In-SBL & 0.84 & $<0.001$ & 0.70 & $<0.001$ \\
Passive & 0.64 & $<0.001$ & 0.50 & $<0.001$ \\
Below-SBL & -0.53 & $<0.001$ & -0.29 & 0.014 \\
\hline
\end{tabular}



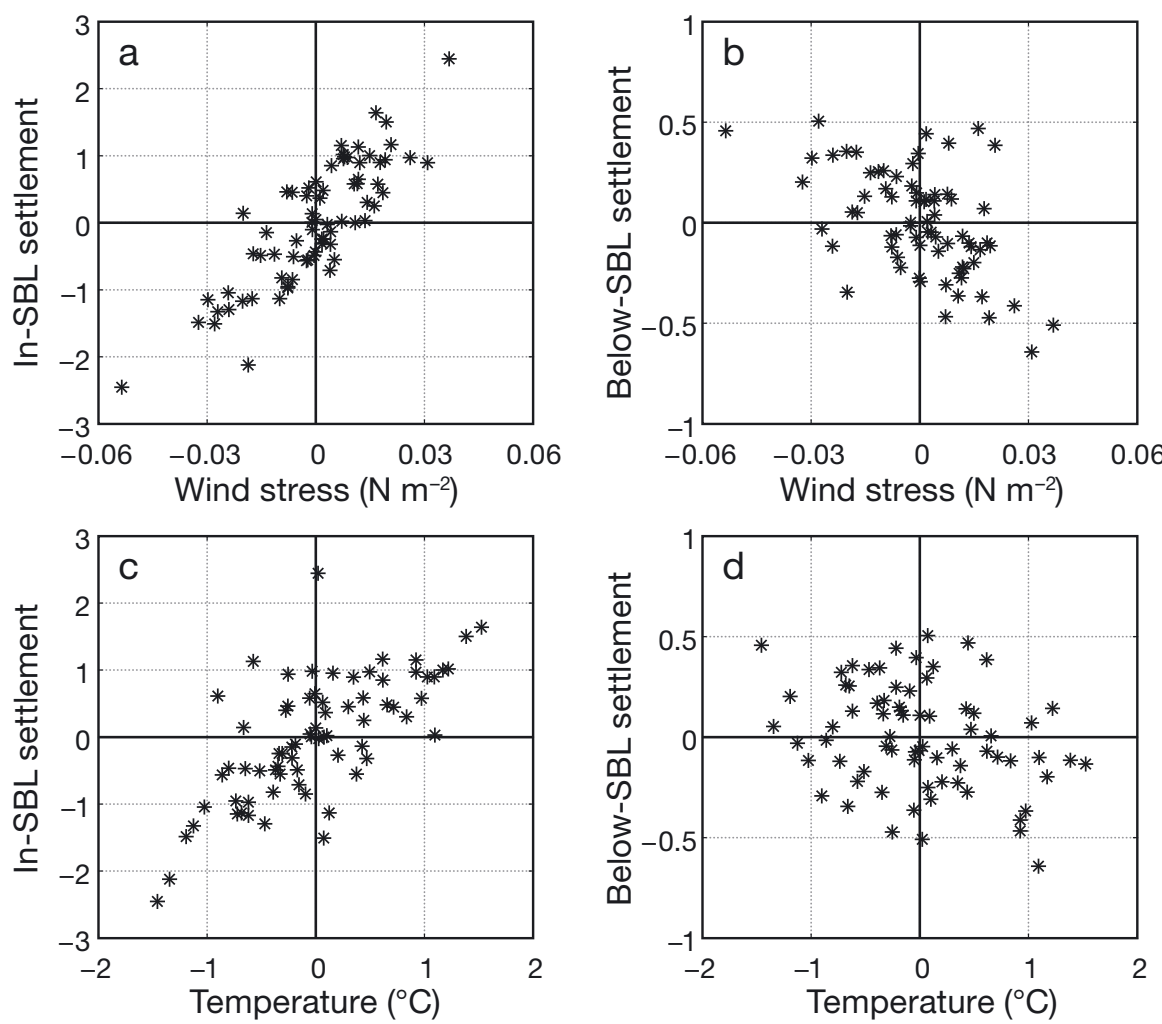

Fig. 9. Monthly anomalies, given a 20-22 d PLD. (a) Wind stress and in-SBL settlement; (b) wind stress and below-SBL settlement; (c) surface temperature and in-SBL settlement; (d) surface temperature and below-SBL settlement.

For abbreviations see Fig. 3

iors (Table 8, Fig. 9c,d). However, similar to the bidaily results, correlation magnitudes are smaller than the corresponding wind stress values. These differences are significant for the DVM and in-SBL behaviors only.

\section{DISCUSSION}

Recent decades have witnessed keen interest in how variations in wind stress, wind-driven upwelling and other environmental variables influence larval dispersal, settlement and the dynamics of nearshore benthic communities (Roughgarden et al. 1988, Sponaugle et al. 2002, Shanks \& Shearman 2009, Pineda et al. 2010). Using a high-resolution, realistic numerical simulation of the CCS from 2001 to 2006, we conducted an extensive statistical investigation into how temporal variations in alongshore wind stress and nearshore temperature relate to larval transport and settlement in central California, a region of persistent springtime upwelling. We considered a range of PLDs (10 to $40 \mathrm{~d}$ ) and a variety of modeled larval behaviors: passive (i.e. no behavior),
DVM, upper $10 \mathrm{~m}$ (in-SBL) and near $30 \mathrm{~m}$ depth (below-SBL).

\section{Wind stress controls settlement}

The results strongly support the argument that alongshore wind stress nearshore drives settlement at timescales ranging from several days to the annual cycle. We find that wind stress is statistically related to settlement both seasonally and within seasons, and for all PLDs studied. Wind stress averaged over the PLD was a better predictor of settlement than a shorter, $2 \mathrm{~d}$ wind stress average. PLD-averaged wind stress accounted for more than half of transformed settlement variance, regardless of the vertical swimming behavior employed by the larvae. A robust settling dependence on wind stress was calculated whether considering the full fields or anomalies relative to their climatological cycles, and whether considering a broad average of the central California coast or small subregions that span only a few tens of kilometers alongshore. We find that regionally averaged wind stress is generally a better predictor of local settlement than is local wind stress averaged within subregions.

The overall effect of alongshore wind stress depends on larval behavior and exposure to the SBL. In our model, settlement for larvae that remain in, or are even partially exposed to, the SBL is substantially and negatively impacted by upwelling-favorable wind stress as envisioned in some of the earliest research on the topic (Roughgarden et al. 1988). Drake et al. (2013) find that different behaviors impact overall settlement and alongshore connectivity dramatically during springtime upwelling conditions. Here, total settlement both within and over all seasons differs substantially among larval behaviors, but DVM and passive larvae show a similar statistical correlation with wind stress to larvae that maintain a near-surface depth. Only larvae that remain below the SBL throughout development can reverse or avoid the negative effects of upwelling-favorable wind stress. However, during winter months, maintaining a depth below the SBL negatively impacts settlement. 
The similarity between wind stress responses for the DVM and in-SBL behaviors illustrates the importance and relative effectiveness of offshore transport in the SBL, even if experienced only partially each day. This similarity was surprising, given the opposite wind stress response displayed by the in-SBL and below-SBL cases, which together compose the DVM behavior. This similarity persisted throughout all seasons. In terms of the overall amount of settlement, the composite DVM behavior lies between the extremes of its 2 parent behaviors, but is much closer to the in-SBL case. For an individual DVM larva in our model, offshore transport in the SBL at night easily overwhelms any onshore transport experienced below the SBL during the day.

\section{Temperature also predicts settlement}

Temperature was also a good predictor of settlement. We find that settlement and temperature are best correlated when temperature is averaged over the larval settlement window, rather than the PLD, and when the climatological cycle has been removed from both records. If not removed, the seasonal offset between maximum temperature in summer and maximum settlement for most behaviors in winter leads to relatively weak correlations for these variables. With the seasonal cycle removed, temperature accounted for between 7 and $38 \%$ of the settlement variance, depending on behavior. We find that wind stress is a significantly better predictor of settlement than surface temperature, and this result is obtained consistently at all timescales greater than the PLD. Unlike wind stress, local temperature within subregions of the coast is generally a better predictor of local settlement than regionally averaged surface temperature.

\section{Relationship to existing studies}

The strong relationship between wind stress and settlement is consistent with some CCS modeling studies (Kim \& Barth 2011), but differs from the calculations of buoyant larvae by Mitarai et al. (2008). That work examined larval dispersal within an idealized, alongshore-uniform, wind-driven coastal upwelling system using stratification, bathymetry and surface forcing statistics representative of the CCS. Although wind stress was found to contribute to larval settlement during one event, the majority of settlement events were related instead to the stirring of the coastal ocean by mesoscale eddies. The intrinsic variability of the circulation was sufficiently large to overwhelm the directly wind-driven Ekman transport, effectively yielding unpredictable settlement statistics consistent with a stochastically forced system (Siegel et al. 2008).

In our realistic configuration, which is rich with mesoscale and submesoscale variability, we find instead that settlement is dominated by extrinsically forced motion. Indeed, using a linear model, PLDaveraged alongshore wind stress accounts for $86 \%$ of the variance of in-SBL settlement ( $77 \%$ if using the untransformed values), and transformed DVM settlement is coherent with wind stress at values over 0.8 for periods from $30 \mathrm{~d}$ to $1 \mathrm{yr}$. Differences in model implementation may account for the different conclusions among modeling studies. Our realistic configuration includes alongshore variability in coastline and shelf width, which may limit the direct, nearshore influence of offshore mesoscale eddies, although Siegel et al. (2008) also considered coastline variations in their model and did not find sensitivity to this factor. The idealized configuration used by both Mitarai et al. (2008) and Siegel et al. (2008) applied periodic meridional boundary conditions and a constant Coriolis parameter, which clearly influences offshore propagation of mesoscale features, and may contribute to the differences among our studies.

It is also possible that differences among these studies reflect different statistical analyses. Indeed, our findings are more consistent with the recent results of Harrison \& Siegel (2014), who present settlement statistics using the idealized configuration of Mitarai et al. (2008). Like us, they found that sustained alongshore wind stress was a greater predictor of settlement by surface larvae than instantaneous wind relaxation, and that a PLD-averaged wind stress can account for $38 \%$ of the variance in untransformed settlement. If we consider in-SBL settlement during upwelling seasons to allow for the most direct comparison with this study, we find PLDaveraged wind stress can account for 16 to $57 \%$ of the untransformed settlement variance, depending on year, with an interannual mean of $36 \%$, very close to the Harrison \& Siegel (2014) value.

In nature, recruitment rates in the CCS show a strong seasonality for both subtidal (Wilson et al. 2008, Caselle et al. 2010) and intertidal (Broitman et al. 2008) communities. It has been proposed that the life histories of many nearshore species may be adapted to the seasonality of the CCS to maximize settlement (Parrish et al. 1981, Peterson 1998, Shanks 
\& Eckert 2005, Drake et al. 2011). Our results illustrate how vertical swimming behavior by larvae can achieve different seasonal patterns of settlement if fecundity and other factors are held constant. Larvae that remain below the SBL experience enhanced settlement in spring and summer when productivity is highest. Larvae that are exposed to the SBL experience very little settlement during this period, but settle in great abundance during December and January. In central California, larvae of many invertebrate species, such as the barnacle Balanus glandula, recruit during spring, while others, such as the mussle Mytilus californianus, recruit primarily in fall (Broitman et al. 2008). Our results imply that these seasonal differences in recruitment could result in part from differences in swimming behavior, although other biological factors such as fecundity, food availability and post-settlement processes are also likely relevant. For example, remaining below the SBL keeps larvae away from the near-surface zone where primary productivity and necessary food resources are highest, and therefore the high settlement observed for this behavior in spring is likely an overestimate.

In the CCS, there is ample evidence of an association between environmental variations and benthic recruitment within upwelling seasons (Farrell et al. 1991, Wing et al. 1995, Shkedy \& Roughgarden 1997, Broitman et al. 2008, Wilson et al. 2008, Dudas et al. 2009a, Morgan et al. 2009a). In the literature, the connection is typically manifested as a positive correlation between temperature and recruitment. However, a weaker positive correlation may exist with wind stress or upwelling index (Farrell et al. 1991, Shkedy \& Roughgarden 1997) or nearshore currents (Wing et al. 1995, Dudas et al. 2009a), and the relationships may be species dependent (Wing et al. 1995, Wilson et al. 2008, Dudas et al. 2009a, Morgan et al. 2009a). We also find that temperature and settlement are positively correlated for behaviors that expose larvae to the SBL, but at a lag and correlation coefficient value that suggests both variables are responding to the wind stress. Except for one year of the in-SBL behavior, mean wind stress over the PLD was always a better predictor of settlement than temperature averaged over either the PLD or settlement window. The greater predictive ability of temperature in field studies may result from comparisons with instantaneous or short-term averages of wind stress rather than a PLD average. As instantaneous temperature reflects the influence of prior wind stress over timescales comparable to the PLD, it may be a better predictor than instantaneous wind stress, even if lagged. Alternatively, the difference may result from other differences in statistical methods, small-scale physical processes not included in our model, or the dependence of pre- and post-settlement processes on temperature. Within upwelling seasons, the species dependence of the relationships between recruitment and environmental variables may also be a result of different swimming behaviors, as discussed above for seasonal variations in wind stress.

An association between temperature and recruitment has also been found at interannual timescales in the CCS, both negative for intertidal invertebrates (Roughgarden et al. 1988, Connolly \& Roughgarden 1999, Iles et al. 2012) and positive for subtidal fishes (Laidig et al. 2007, Wilson et al. 2008, Caselle et al. 2010). Our study extends over only $6 \mathrm{yr}$, which is too short for a robust statistical analysis of interannual relationships. Better understanding of processes governing larval settlement on interannual timescales will be the subject of future studies.

Acknowledgements. We thank 3 anonymous reviewers for their constructive comments that improved the manuscript. We are grateful for support for this research from California Sea Grant (R/FISH-218A) and the National Science Foundation (OCE-1260693). This paper is a contribution of the Bodega Marine Laboratory.

\section{LITERATURE CITED}

Bendat JS, Piersol AG (2000) Random data. John Wiley \& Sons, New York, NY

Broitman BR, Blanchette CA, Menge BA, Lubchenco J and others (2008) Spatial and temporal patterns of invertebrate recruitment along the west coast of the United States. Ecol Monogr 78:403-421

Caselle JE, Carr MH, Malone DP, Wilson JR, Wendt DE (2010) Can we predict interannual and regional variation in delivery of pelagic juveniles to nearshore populations of rockfishes (genus Sebastes) using simple proxies of ocean conditions? Rep CCOFI 51:91-105

Checkley DM, Barth JA (2009) Patterns and processes in the California Current System. Prog Oceanogr 83:49-64

Connolly SR, Roughgarden J (1999) Increased recruitment of northeast Pacific barnacles during the 1997 El Nino. Limnol Oceanogr 44:466-469

Dever EP, Dorman CE, Largier JL (2006) Surface boundarylayer variability off northern California, USA, during upwelling. Deep-Sea Res II 53:2887-2905

Doyle JD, Jiang Q, Chao Y, Farrara J (2009) High-resolution atmospheric modeling of the marine atmospheric boundary layer in support of the AOSN-II field campaign. Deep-Sea Res II 56:87-99

Drake PT, McManus MA, Storlazzi CD (2005) Local wind forcing of the Monterey Bay area inner shelf. Cont Shelf Res 25:397-417

Drake PT, Edwards CA, Barth JA (2011) Dispersion and connectivity estimates along the U.S. west coast from a 
realistic numerical model. J Mar Res 69:1-37

Drake PT, Edwards CA, Morgan SG, Dever EP (2013) Influence of larval behavior on transport and population connectivity in a realistic simulation of the California Current System. J Mar Res 71:317-350

Dudas SE, Grantham BA, Kirincich AR, Menge BA, Lubchenco J, Barth JA (2009a) Current reversals as determinants of intertidal recruitment on the central Oregon coast. ICES J Mar Sci 66:396-407

> Dudas SE, Rilov G, Tyburczy J, Menge BA (2009b) Linking larval abundance, onshore supply and settlement using instantaneous versus integrated methods. Mar Ecol Prog Ser 387:81-95

Farrell TM, Bracher D, Roughgarden J (1991) Cross-shelf transport causes recruitment to intertidal populations in central California. Limnol Oceanogr 36:279-288

- Fisher JL, Peterson WT, Morgan SG (2014) Does larval advection explain latitudinal differences in recruitment across upwelling regimes? Mar Ecol Prog Ser 503:123-137

García-Reyes M, Largier JL (2012) Seasonality of coastal upwelling off central and northern California: new insights, including temporal and spatial variability. J Geophys Res 117:C03028, doi:10.1029/2011JC007629

- Halliwell GR, Allen JS (1987) The large-scale coastal wind field along the west coast of North America, 1981-1982. J Geophys Res 92:1861-1884

Harrison CS, Siegel DA (2014) The tattered curtain hypothesis revised: coastal jets limit cross-shelf larval transport. Limnol Oceanogr Fluids Environ 4:50-66

Iles AC, Gouhier TC, Menge BA, Stewart JS, Haupt AJ, Lynch MC (2012) Climate-driven trends and ecological implications of event-scale upwelling in the California Current System. Glob Change Biol 18:783-796

Kim S, Barth JA (2011) Connectivity and larval dispersal along the Oregon coast estimated by numerical simulations. J Geophys Res 116:C06002, doi:10.1029/2010JC 006741

Laidig TE, Chess JR, Howard DF (2007) Relationship between abundance of juvenile rockfishes (Sebastes spp.) and environmental variables documented off northern California and potential mechanism for the covariation. Fish Bull 105:39-48

Lilliefors HW (1967) On the Kolmogorov-Smirnov test for normality with mean and variance unknown. J Am Stat Assoc 62:399-402

Mitarai S, Siegel DA, Winters KB (2008) A numerical study of stochastic larval settlement in the California Current System. J Mar Syst 69:295-309

Morgan SG, Fisher JL, Mace AJ (2009a) Larval recruitment in a region of strong, persistent upwelling and recruitment limitation. Mar Ecol Prog Ser 394:79-99

Morgan SG, Fisher JL, Miller SH, McAfee ST, Largier JL (2009b) Nearshore larval retention in a region of strong upwelling and recruitment limitation. Ecology 90: 3489-3502

Parrish RH, Nelson CS, Bakun A (1981) Transport mechanisms and reproductive success of fishes in the California Current. Biol Oceanogr 1:175-203
Petersen CH, Drake PT, Edwards CA, Ralston S (2010) A numerical study of inferred rockfish (Sebastes spp.) larval dispersal along the central California coast. Fish Oceanogr 19:21-41

Peterson W (1998) Life cycle strategies of copepods in coastal upwelling zones. J Mar Syst 15:313-326

Pineda J, Hare JA, Sponaugle S (2007) Larval transport and dispersal in the coastal ocean and consequences for population connectivity. Oceanography 20:22-39

Pineda J, Porri F, Starczak V, Blythe J (2010) Causes of decoupling between larval supply and settlement and consequences for understanding recruitment and population connectivity. J Exp Mar Biol Ecol 392:9-21

Rilov G, Dudas SE, Menge BA, Grantham BA, Lubchenco J, Schiel DR (2008) The surf zone: a semi-permeable barrier to onshore recruitment of invertebrate larvae? J Exp Mar Biol Ecol 361:59-74

Roughgarden J, Gaines S, Possingham H (1988) Recruitment dynamics in complex life cycles. Science 241: 1460-1466

Shanks AL (2009) Barnacle settlement versus recruitment as indicators of larval delivery. I. Effects of post-settlement mortality and recruit density. Mar Ecol Prog Ser 385: 205-216

Shanks AL, Brink L (2005) Upwelling, downwelling, and cross-shelf transport of bivalve larvae: test of a hypothesis. Mar Ecol Prog Ser 302:1-12

Shanks AL, Eckert GL (2005) Population persistence of California Current fishes and benthic crustaceans: a marine drift paradox. Ecol Monogr 75:505-524

Shanks AL, Roegner GC (2007) Recruitment limitation in Dungeness crab populations is driven by variation in atmospheric forcing. Ecology 88:1726-1737

Shanks AL, Shearman RK (2009) Paradigm lost? Cross-shelf distributions of intertidal invertebrate larvae are unaffected by upwelling or downwelling. Mar Ecol Prog Ser 385:189-204

Shchepetkin AF, McWilliams JC (2005) The regional oceanic modeling system (ROMS): a split-explicit, free-surface, topography-following-coordinate oceanic model. Ocean Model 9:347-404

Shkedy Y, Roughgarden J (1997) Barnacle recruitment and population dynamics predicted from coastal upwelling. Oikos 80:487-498

Siegel DA, Mitarai S, Costello CJ, Gaines SD, Kendall BE, Warner RR, Winters KB (2008) The stochastic nature of larval connectivity among nearshore marine populations. Proc Natl Acad Sci USA 105:8974-8979

Sponaugle S, Cowen RK, Shanks A, Morgan SG and others (2002) Predicting self-recruitment in marine populations: biophysical correlates and mechanisms. Bull Mar Sci 70: S341-S375

Wilson JR, Broitman BR, Caselle JE, Wendt DE (2008) Recruitment of coastal fishes and oceanographic variability in central California. Estuar Coast Shelf Sci 79:483-490

Wing SR, Largier JL, Botsford LW, Quinn JF (1995) Settlement and transport of benthic invertebrates in an intermittent upwelling region. Limnol Oceanogr 40:316-329

Submitted: July 9, 2014; Accepted: June 12, 2015

Proofs received from author(s): October 1, 2015
Editorial responsibility: Christine Paetzold, Oldendorf/Luhe, Germany 